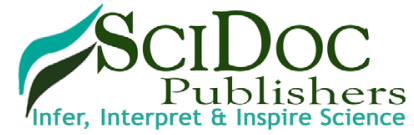

\section{Screening for Chronic Kidney Disease in a Small Developing Country using the National Kidney Foundation Guidelines}

\section{International Journal of Chronic Diseases \& Therapy (IJCDT) ISSN 2572-7613}

Mungrue $\mathrm{K}^{*}$, Khan S, Bisnath R, Jaipaul J, Doodhai J, Ramlal D, Boodram S, Chin-Kong P, Badhal J, Roberts L

Faculty of Medical Sciences, Department of Paraclinical Sciences, University of the West Indies, Public Health and Primary Care, St. Augustine, Trinidad.

\title{
Abstract
}

Objective: The purpose of this study is to screen high risk patients greater than 45 years attending primary care facilities who have undiagnosed CKD and identify this group for further intervention.

Design and Methods: A cross-sectional study design was used. The populations consisted of all adults 45 years and older in a primary care setting. A validated questionnaire was administered to all eligible participants.

Results: A total of 227 participants were entered into the study. No participant refused to participate resulting in a $100 \%$ response rate. One hundred and five participants 105 46.3\% were classified as normal and one hundred and twenty two 122 $53.7 \%$ were classified as having Stages 1-3 CKD. Further, $22(18.0 \%)$ participants were found to be in Stage 3 of CKD.

Conclusion: We provide evidence that screening can detect as much as 18.0\% of asymptomatic individuals with Stage 3 CKD.

Keywords: Chronic Kidney Disease (CKD); Estimated Glomerular Filtration Rate (eGFR); Stage 3 CKD; End Stage Renal Disease (ESRD).

\section{Introduction}

Over the past two decades (1990-2010), deaths from chronic kidney disease (CKD) rose to almost $82 \%$ worldwide, the third largest increase among the top 25 causes of death after HIV / AIDS and diabetes. In England $£ 1.45$ billion was spent on caring for people with CKD in 2009-10 [1]. The Caribbean has the highest prevalence of chronic non communicable diseases (CNCD) in the region of the Americas, of which CKD is an important contributor [2]. PAHO in its 2008 report stated that deaths due to CNCD were 673 per 100,000 in Trinidad and Tobago [3]. In 2011, the Ministry of Health $(\mathrm{MoH})$ reported 699 patients on dialysis treatment at public and private health facilities throughout Trinidad and Tobago $[4,5]$. In 2010, the $\mathrm{MoH}$ signed a contract with the British-based company Fresenius Medical Care and Biomedical Technologies for operation of haemodialysis units which were estimated to cost the state $\$ 108,675,375.00$ (TT) annually [6]. The state is also continuing to subsidised dialysis treatment by paying a monthly grant of $\$ 5,000$ (T'T) to recipients needing dialysis, thus further emphasising the urgent need to reduce the incidence of CKD and its progression to end-stage renal disease (ESRD) [7]. Several studies have demonstrated a positive correlation between CKD and type 2 diabetes mellitus (T2DM) and hypertension, both of which are the major contributors in our setting [8-11]. Soyibo et al., in 2006 reported that more than $50 \%$ of all cases of Stage 5 CKD in Trinidad was associated with DM (28.9\%) or hypertension (25.3\%) [8]. This is against a background in which the adverse outcomes of CKD including kidney failure and premature death are preventable [12], through screening of at risk, asymptomatic individuals [12-15].

A critical web exists between awareness of risk, the presence of disease, and steps taken by the patient and clinician to change the natural history of disease. Chronic illnesses such as diabetes mellitus, dyslipidaemia, anaemia and a multitude of endocrinological and rheumatological diseases are relatively silent and rely on the clinical laboratory for diagnosis, particularly in their early stages. Probably no such illness permits such a large loss of organ function before symptoms become present than

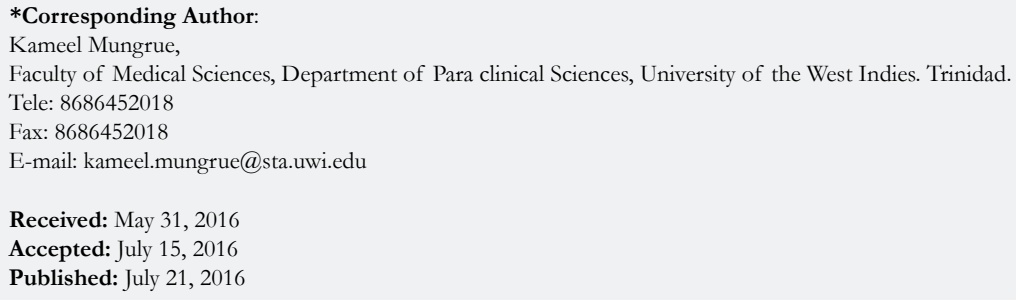

Citation: Mungrue K, Khan S, Bisnath R, Jaipaul J, Doodhai J, et al., (2016) Screening for Chronic Kidney Disease in a Small Developing Country using the National Kidney Foundation Guidelines. Int J Chronic Dis Ther. 2(4), 39-41. doi: http://dx.doi.org/10.19070/2572-7613-160007

Copyright: Mungrue $\mathbf{K}^{\circ}$ 2016. This is an open-access article distributed under the terms of the Creative Commons Attribution License, which permits unrestricted use, distribution and reproduction in any medium, provided the original author and source are credited. 
CKD [16]. Thus, the considerable dependence on the laboratory to establish the diagnosis of CKD is an issue for low-income and middle-income countries (LMIC), where access to in-vitro diagnostics on a screening basis might not be universally available. Even in high-income countries where routine laboratory tests are performed, CKD seems to lag considerably behind diabetes mellitus, hypertension, and cardiovascular disease in terms of patient and clinician awareness [17]. This difference is partly due to the two-dimensional nature of $\mathrm{CKD}$ defined as a reduction in estimated glomerular filtration rate (eGFR) and the presence of markers of chronic kidney damage (albuminuria or imaging evidence) over 3 months time. Thus, to have the eGFR and albumin/creatinine ratio at the same time clearly inform the patient of the potential presence of CKD is complex. With these challenges as the backdrop, the aim of this study is to screen patients greater than 5 years attending primary care facilities for undiagnosed $\mathrm{CKD}$ in order to provide the evidence to support this intervention.

We used a cross-sectional study design. The population consisted of all patients attending primary health care facilities (PHCF) in the Eastern Regional Health Authority (ERHA) which has an estimated population of 120,000 persons. In this region, primary health care is delivered through fifteen (15) PHCF (clusters) of which seven were randomly selected to meet our calculated sample of 227 . All adult patients greater than 5 years with T2DM, hypertension or both were eligible for entry into the study. Pregnant patients, patients with obstructivenephropathy, polycystic kidney disease, lupus nephritis and existing stages 4 and $5 \mathrm{CKD}$ were excluded from the study.

Demographic data and clinical data such as blood pressure, current treatment, duration of comorbidities, waist circumference, weight $(\mathrm{kg})$, height $(\mathrm{m})$ and BMI were collected. Also included were laboratory results for urinalysis, blood glucose, HbA1c and serum creatinine. The serum creatinine was used to calculate the estimated Glomerular Filtration Rate (eGFRCr) using the epidemiological formula: eGFRCr $=141 \mathrm{x} \min (\operatorname{Scr} / x, 1)^{\alpha} \mathrm{x}$ $\max (\mathrm{Scr} / x, 1)^{-1.209} \times 0.993^{\mathrm{Age}} \times 1.018$ [if female] $\times 1.159$ [if black], where Scr is serum creatinine $(\mathrm{mg} / \mathrm{dL}), \kappa$ is 0.7 for females and 0.9 for males, $\alpha$ is -0.329 for females and -0.411 for males, " $m i n$ " indicates the minimum of $\mathrm{Scr} / \kappa$ or 1 , and " $\max$ " indicates the maximum of $\mathrm{Scr} / \kappa$ or 1 [18].

Blood pressure was measured using a mercury sphygmomanometer using standard techniques, two measurements were made in both the right and left arms and the average recorded [19]. Hypertension was defined as a BP>140/90 (JNC8) [20] and T2DM was defined as a physician diagnosis with or without the use of an oral hyperglycaemic agent, insulin or a fasting blood sugar $>126 \mathrm{mg} / \mathrm{dL}$, a random blood sugar of $>200 \mathrm{mg} / \mathrm{dL}$ or a HbA1c $>7 \%$ [21]. Ethical approval for this study was obtained from the University of the West Indies' Ethics Committee. All data was stored, retrieved and analysed using SPSS vs 22.0.

\section{Results}

All 227 participants who met the entry criteria for the study were available for analysis. The mean age was 63.07 years $(\mathrm{SD} \pm 9.7)$ with an interquartile range of 56-70 years. The majority of participants $83(36.6 \%)$ were in the age group 55-64 years. There were more females than males with a female:male ratio of 1.8:1.The sample consisted of more persons of South Asian origin 130, (57.3\%) than of African origin 71 (31.3\%), although both represent 35\% of the population [22]. Of the 227 patients entered into the study, 105 patients had a normal eGFRCr $\left(\geq 90 \mathrm{ml} / \mathrm{min} / 1.732 \mathrm{~m}^{2}\right)$ and no clinical evidence of proteinuria. Thus, 122 participants were found to have stages 1-3 CKD. Therefore, $122(53.7 \%)$ patients had confirmed CKD of which the majority 81 (66.4\%) were in Stage 2 (eGFRCr of $60-89 \mathrm{ml} / \mathrm{min} / 1.732 \mathrm{~m}^{2}$ ). However, the major finding of the study was $18.0 \%$ (95\% CI-13\%-23\%) of participants had Stage 3 CKD. Since the study was conducted in an outpatient clinic, it is unlikely that patients with Stage 4 or 5 CKD would be attending the clinic.

Further analysis revealed that there was a significant temporal relationship with the occurrence of CKD. CKD (Stage 1-3) was significantly higher $(\mathrm{p}=.004)$ in participants with T2DM and hypertension for greater than 5 years $59(85.5 \%)$ than those with $\mathrm{T} 2 \mathrm{DM}$ and hypertension for greater than 5 years $10(14.5 \%)$. Among all 227 participants, hypertension was more common 184 (81.1\%) than T2DM $128(56.4 \%)$, and $92(40.5 \%)$ patients had both hypertension and T2DM. Approximately one quarter of the patients already had established coronary heart disease $21(9.3 \%)$ and dyslipidaemia $52(22.9 \%)$. Overall only 4 patients $(1.7 \%)$ had no evidence of any underlying comorbidity. The majority of participants $111(48.9 \%)$ were either retired or unemployed and therefore not earning an income. 198 (87.2\%) patients had a family history of either T2DM or hypertension and $27(11.9 \%)$ had a family history of CKD. Using logistic regression analysis there was a significantly higher odds ratio for CKD by age and ethnicity. Of concern was only $87(38.3 \%$ ) participants had an HbA1c, mainly among patients with T2DM (34) of which 22 $(64.7 \%)$ was greater than $7 \%$.

\section{Discussion}

The major finding of the study was screening identified 22 (18.0\%), (95\% CI: 13-23) previously undiagnosedcases of Stage 3 CKD. Stage 3 CKD occurred predominantlyin the age group 65-84 years and among patients with obesity (68.2\%), T2DM $(63.6 \%)$, and hypertension (86.4\%). In the Third National Health and Nutrition Examination Survey [23], a nationally representative sample of the U.S. population, $13 \%$ of adults with T2DM had a GFR less than $60 \mathrm{ml} / \mathrm{min} / 1.73 \mathrm{~m}^{2}$, consistent with stage 3 CKD. Several large studies have reported a proportion of Stage 3 CKD ranging from $4.3-15.6 \%$ [23, 24]. It is apparent that Trinidad has a high prevalence of Stage 3 CKD, emphasising the need for screening programs to detect CKD. Screening programs are generally aimed at conditions with a substantial public health impact for which there is benefit from early interventions. CKD certainly fits this criterion. CKD Stage 3 is associated with an increased incidence of both renal failure and death compared to the general population, particularly for those younger than 70 years [25]. Studies of Stage 3 CKD have also shown that over a 10 year period, $34.6 \%$ will progress to Stage 4 CKD and $26.2 \%$ will progress Stage $5 \mathrm{CKD}$ requiring renal replacement therapy [25]. Notwithstanding, cardiovascular disease far outweighs the risk of renal failure [26]. The majority of patients 21 (95.45\%) with stage 3 CKD had both T2DM and hypertension for greater than 5 years, both factors are significant predictors of Stage 3 CKD (OR 8.25, 95\%CI: 1.02-8.18, $\mathrm{p}=0.042$ ). In addition $198(87.2 \%)$ 
patients had a family history of CKD which was also identified as a significant risk factor (OR 2.01, $\mathrm{p}=0.03$ ) for the development of CKD, consistent with the literature [27].

Overall, $122(53.7 \%)$ participants had stages 1-3 CKD. The occurrence of CKD was significantly $(\mathrm{p}<0.05)$ more common in women $73(59.8 \%)$ than men $49(40.2 \%)$ and occurred most common $46(37.7 \%)$ in the age group $65-74$ years. Several studies have reported a similar pattern [24, 28-31].

As Stages 1-3 CKD, occurred in older age groups, it was not unusual to find that most of these patients were unemployed 103 (84.4\%) or receiving government assistance and therefore not financially equipped to suitably manage their disease. Therefore impacting adversely on quality of life as well as adding an additional burden to the state.

The major limitation of the study was the unavailability of laboratory support to determine the albumin/creatinine ratio which is a key marker of chronic kidney disease, emphasising not only gaps in the clinical care of patients but the challenges confronted in the developing world. Hence, the study was restricted to eGFR estimations. A single eGFR may also contribute to misclassification bias.

In conclusion our data seem to present a three-part challenge: (1) to screen and detect CKD, (2) to become aware of the condition, and (3) to understand and act on the knowledge that controlling modifiable risk factors like blood pressure and glucose can attenuate progression of CKD. In the end it all starts with screening and detection of a silent disease, which give years of opportunity for discovery and modification of its natural history.

\section{References}

[1]. (2014) Chronic kidney disease: refining diagnosis and management. The Lancet 384(9941): 378.

[2]. Pan American Health Organization. Health situation in the Americas: basic indicators. World Health Organization. 2010.

[3]. World Health Organization. World Health Statistics. World Health Organization. 2013.

[4]. Ministry of Health, Government of Trinidad and Tobago. World Kidney Day. http://health.gov.tt/news/newsitem.aspx?id=333 (accessed August 2014).

[5]. Ministry of Health, Government of Trinidad and Tobago. World Kidney Day. http://health.gov.tt/news/newsitem.aspx?id=333 (accessed August 2014).

[6]. The Minister Of Health, The Honourable Jerry Narrace. Contract signing ceremony for the construction of renal dialysis centres. http://www.health. gov.tt/downloads/DownloadDetails.aspx?id=169 (accessed August 2014).

[7]. Soyibo K, Roberts L, Barton EN (2011) Chronic kidney disease in the Caribbean. West Indian Med J. 60(4): 464-470.

[8]. Soyibo K, Barton EN (2007) Report from the Caribbean renal registry, 2006. West Indian Med J 56(4): 355-363.

[9]. Ravera M, Re M, Deferrari L, Vettoretti S, Deferrari G (2006) Importance of blood pressure control in chronic kidney disease. J Am Soc Nephrol 17(4): S98-S103.

[10]. Lou Arnal LM, Campos Gutiarrez B, Cuberes Izquierdo M, Gracia Garcia O, Bielsa Garcia S, et al., (2010) Prevalence of chronic kidney disease in patients with type 2 diabetes mellitus treated in primary care. Nefrologia 30(5): 552-556.

[11]. Yoshida T, Kato K, Yokoi K, Watanabe S, Metoki N, et al., (2009) Association of genetic variants with chronic kidney disease in Japanese individuals with type 2 diabetes mellitus. Int J Mol Med 23(4): 529-537.

[12]. Levey AS, Coresh J, Balk E, Kausz AT, Levin A, et al., (2003) National Kidney Foundation practice guidelines for chronic kidney disease: Evaluation, classification, and stratification. Ann Intern Med 139(2): 137-147.

[13]. Freedman BI, Kopp JB, Langefeld CD, Genoveses G, Friedman DJ, et al., (2010) The apolipoprotein L1 (APOL1) gene and nondiabetic nephropathy in African Americans. J Am Soc Nephrol 21(9): 1422-1426.

[14]. Manns B, Hemmelgarn B, Tonelli M, Au F, Chiasson TC, et al., (2010) Population based screening for chronic kidney disease: cost effectiveness study. BRIT J MED (341): 58-69.

[15]. Birbeck GL (2000) The benefits of screening must outweigh the risks and costs. West J Med 172(5): 308-309.

[16]. McCullough PA (2003) Beyond serum creatinine: defining the patient with renal insufficiency and why?. Rev Cardiovasc Med 4: S2-S6.

[17]. Saab G, Whaley-Connell AT, McCullough PA, Bakris GL (2008) CKD awareness in the United States: the Kidney Early Evaluation Program (KEEP). Am J Kidney Dis 52(2): 382-383.

[18]. Levey AS, Stevens LA, Schmid CH, Zhang YL, Castro AF, et al., (2009) A new equation to estimate glomerular filtration rate. Ann Intern Med 150(9): 604-612.

[19]. National High Blood Pressure Education Program. The seventh report of the Joint National Committee on prevention, detection, evaluation, and treatment of high blood pressure. National Heart, Lung, and Blood Institute (US). Report number: 7, 2004.

[20]. James PA, Oparil S, Carter BL, Cushman WC, Dennison-Himmelfarb C, et al., (2014) 2014 Evidence-based guideline for the management of high blood pressure in adults. JAMA 311(5): 507-520.

[21]. International Diabetes Federation. Definition and diagnosis of diabetes mellitus and intermediate hyperglycemia. World Health Organisation. 2006.

[22]. Ministry Of Planning and Sustainable Development. Trinidad and Tobago 2011 population and housing demographic report. Government Of The Republic Of Trinidad and Tobago. 2011.

[23]. Coresh J, Astor BC, Greene T, Eknoyan G, Levey AS (2003) Prevalence of chronic kidney disease and decreased kidney function in the adult US population: Third National Health and Nutrition Examination Survey. Am. J. Kidney Dis 41(1): 1-12.

[24]. Annear NMP, Banerjee D, Joseph J, Harries TH, Rahman S, et al., (2008) Prevalence of chronic kidney disease stages 3-5 among acute medical admissions: another opportunity for screening. QJM: 101(2): 91-97.

[25]. Eriksen BO, Ingebretsen OC (2006) The progression of chronic kidney disease: a 10-year population-based study of the effects of gender and age. Kidney Int 69(2): 375-382.

[26]. Go AS, Chertow GM, Fan D, McCulloch CE, Hsu CY (2004) Chronic kidney disease and the risks of death, cardiovascular events, and hospitalization. N Engl J Med 351(12): 1296-1305.

[27]. Garg AX, Papaioannou A, Ferko N, Campbell G, Clarke JA, et al., (2004) Estimating the prevalence of renal insufficiency in seniors requiring longterm care. Kidney Int 65(2): 649-653.

[28]. McClellan W, Warnock DG, McClure L, Campbell RC, Newsome BB, et al., (2006) Racial differences in the prevalence of chronic kidney disease among participants in the reasons for geographic and racial differences in stroke (REGARDS) cohort study. J Am Soc Nephrol. 17(6): 1710-1715.

[29]. Hallan SI, Coresh J, Astor BC, Asberg A, Powe NR, et al., (2006) International comparison of the relationship of chronic kidney disease prevalence and ESRD risk. J Am Soc Nephrol.17(8): 2275-2284.

[30]. Foster MC, Hwang SJ, Larson MG, Lichtman JH, Parikh NI, et al., (2008) Overweight, obesity, and the development of stage 3 CKD: the Framingham Heart Study. Am J Kidney Dis 52(1): 39-48.

[31]. Nomura I, Kato J, Kazuo K (2009) Association between body mass index and chronic kidney disease: a population-based, cross-sectional study of a Japanese community. Vasc Health Risk Manag 5(1): 315-320. 